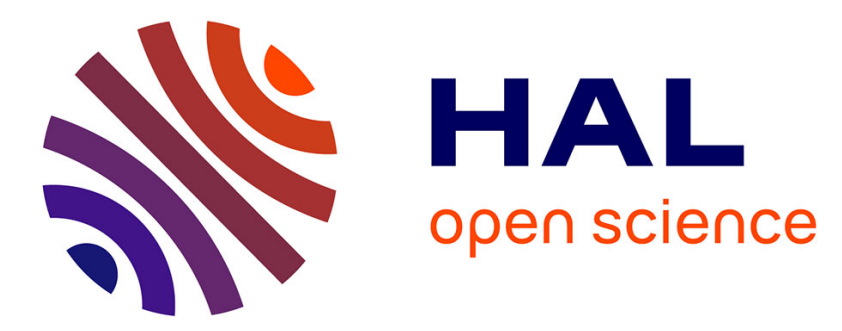

\title{
Mimofonías. En la masmédula de Girondo o la ficción de la lengua
}

Dardo Scavino

\section{To cite this version:}

Dardo Scavino. Mimofonías. En la masmédula de Girondo o la ficción de la lengua. Bulletin Hispanique, 2005, 107 (2), pp.519-544. 10.3406/hispa.2005.5240 . hal-02300816

\section{HAL Id: hal-02300816 https://hal.science/hal-02300816}

Submitted on 29 Sep 2019

HAL is a multi-disciplinary open access archive for the deposit and dissemination of scientific research documents, whether they are published or not. The documents may come from teaching and research institutions in France or abroad, or from public or private research centers.
L'archive ouverte pluridisciplinaire HAL, est destinée au dépôt et à la diffusion de documents scientifiques de niveau recherche, publiés ou non, émanant des établissements d'enseignement et de recherche français ou étrangers, des laboratoires publics ou privés. 


\title{
Mimofonías. En la masmédula de Girondo o la ficción de la
}

\section{lengua}

In: Bulletin Hispanique. Tome 107, N², 2005. pp. 519-544.

\begin{abstract}
En la masmédula by Oliveiro Girondo brings up a problem : think of the mimetic dimension of the language which seems to be out of any lexical, morphological orphono- logical segmentation. With the concept of « mimophonia », as mellas the pseudocategory of « mimema », this article resumes the Freudian project of desiring linguistics called « linguistry » by Jacques Lacan, at the beginning ofthe seventies.
\end{abstract}

\section{Resumen}

En la masmédula de Oliverio Girondo plantea un desafío : pensar esa dimensión mimética de la lengua que parece sustraerse a la segmentación lexical, morfológica o fonológica. Con el concepto de « mimofonía » y la seudo-categoría de « mimema », este artículo pretende retomar el proyecto freudiano de esa lingüística deseante que Jacques Lacan llamará « lingüistería » a principios de los años setenta.

\section{Résumé}

En la masmédula de Oliverio Girondo lance un défi : penser cette dimension mimétique de la langue qui semble échapper à la segmentation lexicale, morphologique ou phonologique. En introduisant le concept de « mimophonie », ainsi que la pseudocatégorie de " mimeme », cet article reprend le projet freudien d'une linguistique désirante que Jacques Lacan appellera « linguisterie » au début des années soixante-dix.

Citer ce document / Cite this document :

Scavino Dardo. Mimofonías. En la masmédula de Girondo o la ficción de la lengua. In: Bulletin Hispanique. Tome 107, N², 2005. pp. 519-544.

doi : 10.3406/hispa.2005.5240

http://www.persee.fr/web/revues/home/prescript/article/hispa_0007-4640_2005_num_107_2_5240 


\title{
Mimofonías. En la masmédula de Girondo o la ficción de la lengua
}

\author{
DARDO SCAVINO \\ Université de Bordeaux 3
}

En la masmédula de Oliverio Girondo lance un défi : penser cette dimension mimétique de la langue qui semble échapper à la segmentation lexicale, morphologique ou phonologique. En introduisant le concept de "mimophonie", ainsi que la pseudocatégorie de "mimème ", cet article reprend le projet freudien d'une linguistique désirante que Jacques Lacan appellera "linguisterie " au début des années soixante-dix.

En la masmédula de Oliverio Girondo plantea un desafio : pensar esa dimensión mimética de la lengua que parece sustraerse a la segmentación lexical, morfologica o fonologica. Con el concepto de "mimofonía " y la seudo-categoría de "mimema", este artículo pretende retomar el proyecto freudiano de esa lingüistica deseante que Jacques Lacan llamará " lingüistería" a principios de los años setenta.

En la masmedula by Oliveiro Girondo brings up a problem : think of the mimetic dimension of the language which seems to be out of any lexical, morphological or phonological segmentation. With the concept of "mimophonia", as well as the pseudo-category of "mimema", this article resumes the Freudian project of desiring linguistics called "linguistry" by Jacques Lacan, at the beginning of the seventies.

Mots-clés : Mot-valise - Cryptogrammes - Anagrammes - Métanalyse Métathèse.

B. $H i ., \mathrm{n}^{\circ} 2$ - décembre 2005 - p. 519 à 544. 


\section{INTRODUCCION}

$\mathrm{E}$ NRIQUE Molina percibía en los dos primeros versos de En la masmédula ( No sólo / el fofo fondo») tanto "la idea evocada por el signo, lo fofo», como «la grave acumulación de las $o$ y la repetición fo-fo-fo... que sugiere un ruido sordo de hongos que revientan, de algo esponjoso, blanduzco, donde se hunden los pasos" ${ }^{1}$. Retomando el léxico de Genette, podría sostenerse que Molina adscribe en este pasaje a una visión cratílica de la palabra poética, entendida como "motivación directa o mimética» ${ }^{2}$ de su dimensión fónica: a través de su imagen acústica el significante imitaría su propio significado, o incluso su designatum: habría una analogía entre sonido y sentido o entre fonemas y cosas.

Pero esta lectura no tarda en tropezar con la objeción saussuriana: incluso las onomatopeyas varían de una lengua a otra, y es precisamente el caso de la palabra fofo. Para un francés, que diría flasque, o para un inglés, que optaría por flabby, el sonido de los pasos sobre un suelo blanduzco ya no será sugerido por la asonancia en $/ o /$ ni por la sílaba $/ f o /$ sino, acaso, por la partícula $/ f-l$, de modo que ninguno de los dos la asociaría con las susodichas esponjas sino tal vez con la nieve, por sinécdoque de flocons y flakes, o incluso con alguna materia fluida, debido a las resonancias de los términos fluide, flot o flood. Y a lo mejor tampoco concurrirían los hongos a la asociación mental de aquellos lectores sino más bien las flores, debido esta vez a la aliteración entre flasque y fleurs, flabby y flowers.

Hay pues una motivación que caracteriza efectivamente a los poemas de En la masmédula, pero ya no pasa por la semejanza entre el plano acústico de la palabra y las imágenes de las cosas significadas sino por la homofonía total o parcial entre los propios significantes. De hecho, cuando Molina asocie aquellos dos primeros versos del poema «La mezcla» con «un ruido sord $o$ de hongos que revientan», así como con «algo esponjoso», no hará sino proseguir, o en cierto modo imitar - no en vano se trata de otro poeta-, la asonancia propuesta allí por Girondo, o incluso el eco sonoro proveniente de la imagen acústica f-on-do: hongo, esponjoso, ruido, sordo. Y hasta podría conjeturarse que Girondo ya había seleccionado el vocablo fondo, entre otros sustantivos que hubieran podido ocupar su lugar, porque su significante reúne, como un metaplasmo o condensación, los sinónimos fofo y

1. Enrique Molina, "En la masmédula" in Homenaje a Girondo (edición, introducción y notas de Jorge Schwartz), Buenos Aires, Corregidor, 1987, p. 334.

2. Gérard Genette, Mimologiques. Voyage en Cratylie, Paris, Seuil, 1976. 
blando, algo que no deja de recordar Molina al evocar lo blanduzco, de modo que sería por la aliteración del sonido /nd/ que éste forja el sintagma: "donde se hunden los pasos». A Molina, digamos, los versos no le sugieren sonidos de cosas sino más bien de palabras, o es por homofonía en el plano significante que los significados se asocian configurando una serie semántica singular.

Que En la masmédula remotive los significantes de la lengua, considerados arbitrarios por Ferdinand de Saussure, es una afirmación exacta, sólo que ya no se trataría de una "motivación directa o mimética» sino más bien «indirecta o etimológica» ${ }^{3}$, siempre que se entienda esta expresión en el sentido de una etimología poética, popular, infantil o delirante, vale decir, de una remotivación de los vocablos por vecindad con un significante homofónico. Si mímesis hay, ésta tiene lugar entre los significantes y ya no entre palabras y cosas nombradas, y es en este aspecto que la mimofonía se distingue de la mimología genettiana. Molina, en cierto modo, no hace sino desplegar un paradigma homofónico, una serie de significantes concomitantes asociados por eco sonoro, aliteración o asonancia, pero lo hace como si fuera un paradigma semántico o como si las palabras del verso y las de su comentario pertenecieran a una misma familia, y es en este aspecto que puede hablarse de remotivación de los distintos vocablos. Señalar los diversos niveles de homofonía no resulta, pues, suficiente, porque esto nos dejaría en el plano formalista de una perceptibilidad de la imagen acústica que no afecta el contenido semántico de los poemas.

En el Curso, Saussure incluía estas asociaciones acústicas en el ya célebre esquema de las cuatro series paradigmáticas irradiadas por el término enseignement: 1) enseigner, enseignons, etc., 2) apprentissage, éducation, etc., 3) changement, armement, etc., y 4) clément, justement, etc. ${ }^{4}$ Tenemos, en el primer caso, un paradigma lexicológico, uno semántico en el segundo, una serie morfológica en el tercero y en la cuarta, por fin, una sustitución homofónica. Pero como puede verse, a este cuarto paradigma no le basta con ser homofónico: imita, engañosamente, el tercero. Las terminaciones en /-ment/, sin embargo, no se confunden, para el lingüista, con las del tercer paradigma. En justement ya no se trata, como en enseignement, changement o armement, de un morfema que sustantiviza un verbo (enseigner, changer, armer) sino de otro, distinto, que adverbializa un aquí adjetivo (juste). En el caso de clément, el morfema ya no es ni siquiera /-ment/ sino/-ent/, y su

3. Ibid.

4. Ferdinand de Saussure, Cours de linguistique générale, Paris, Payot, 1979, p. 175. 
BULLETIN HISPANIQUE

función consiste en adjetivar el lexema / clem/ como en prudent o évident. La $\mathrm{l} / \mathrm{m} /$ pertenece entonces a ese lexema y ya no al morfema en cuestión. De modo que este paradigma no es simplemente homofónico sino también seudo-morfológico: simula ser la continuación del tercero sin llegar a serlo en verdad. Incluso Saussure hubiese podido hacer lo propio con el primer paradigma y añadir una serie de seudo-lexemas por homofonía, aunque tal vez hubiera debido escoger otro vocablo, como por ejemplo terminer: termite, thermos, etc.

El estudio estructural de la lengua, sin embargo, suponía la exclusión de estas mimofonías como meras contingencias sonoras que sólo nos inducen a confusión, cuando no a pergeñar aquellas «etimologías populares» condenadas por el profesor suizo en sus clases - pero que vuelven, como lo reprimido, en los cuadernos sobre los anagramas ${ }^{5}$. El lingüista del Curso ya no debe buscar la semejanza sino lo mismo: en el primer paradigma se trata de los mismos lexemas a los que se les añade morfemas diversos, mientras que en el tercero se trata de los mismos morfemas añadidos a lexemas distintos. En ambos casos no nos encontramos ante fenómenos de imitación sino de combinación. Incluso la "motivación relativa» que Saussure reconoce, pertenece al orden de la identidad y no de la semejanza, porque se trata de los mismos lexemas, o eventualmente de los mismos morfemas. El

5. Además del Cratilo de Platón, en donde Sócrates las multiplica, un caso ya célebre de estas etimologías poéticas o populares condenadas por el Saussure del Curso se encontraba en el Etymologiarum de Isidoro de Sevilla, algunas de cuyas ocurrencias vale la pena recordar porque no carecen de semejanza con las mimofonías de Girondo. Así amicus (amigo) condensaba, según este sacerdote, la expresión animi custos (guardián del alma), mientras que beatus (feliz) hacía lo propio con bene actus (que se desenvuelve bien). San Isidoro no percibía en el sustantivo magister una adjunción del morfema /-ter/ al adverbio magis sino una condensación de maior in statione (el puesto más elevado), de modo que unía, a la manera del adjetivo clément en el esquema del Curso, la /s/ de magis con la /t/del morfema /-ter/ para encontrar allí la raíz /st-/del sustantivo statione. Algo similar planteaba este clérigo al sostener que el sustantivo reges (rey) tiene su origen en la expresión recte agendo (actuar rectamente). Según el obispo de Sevilla, el conocimiento de la etimología nos permitiría conocer así la esencia divina de las criaturas. Que homo (hombre) proviniera de bumus (tierra), y que esta etimología fuese convalidada por el mito bíblico, le parecía prueba suficiente para sugerir, aunque no sean sus términos, que los vocablos de la lengua son criptogramas en los cuales puede encontrarse el origen y la verdadera definición de las cosas: verbum es verum. Como para el Platón del Cratilo, la cábala o el Saussure de los anagramas, estos criptogramas suponían, para San Isidoro, la existencia de un onomaturgo, vale decir, de un «sujeto supuesto saber» creador de los nombres (Dios, en su caso), algo que, precisamente, niega la lingüística estructural inspirada en el Curso, para la cual ya no hay sujeto de la lengua sino sólo del habla. Isidoro de Sevilla, Etymologiarum (edición de J. Oroz Reta), Madrid, BAC, 1982. 
reconocimiento de esta motivación se hace pues bajo el control estricto de la hipótesis indoeuropea. Pero que se puedan encontrar en la misma lengua, o en otra, cadenas fónicas semejantes a las que constituyen esos lexemas y esos morfemas, y que éstas no se justifiquen por la filiación indoeuropea, es un puro azar del que no se ocupa el lingüista. No hay ningún motivo para que una sucesión de fonemas se asocie a tal o cual significación o función, y la tesis de la arbitrariedad del signo linguístico no significa otra cosa. Que en español la sílaba /de/ funcione como una preposición o como un imperativo del verbo dar, es algo que no le atañe a la lingüística tal como la entiende Saussure, quien se preocuparía, en todo caso, por discernir ambas ocurrencias para evitar confusiones. No debe sorprendernos entonces que una sucesión semejante adquiera, en otra secuencia, una significación diferente. De donde se infiere que lo arbitrario vale no sólo para las relaciones entre signos y cosas, o incluso entre significantes y significados, sino también para las analogías de los propios significantes entre sí.

Convertir la lingüística en ciencia significaba, para Saussure, abandonar el terreno de la semejanza o la mímesis. Del pseudos ${ }^{6}$. Evitar esos momentos en que la lengua se ficcionaliza, en donde una palabra, o un segmento significante cualquiera, se hace pasar, engañosamente, por otro. Para tomar el caso de los morfemas, digamos que el sonido /-a / en español puede corresponder a una conjugación de tercera persona del singular, por oposición a la /-o / de la primera persona, pero también a un morfema femenino, por oposición, esta vez, a la /-o / de los masculinos. El uso del mismo fonema en ambas ocurrencias resulta pues azaroso. Saussure hubiera dicho, pues, arbitrario. De modo que, una vez más, la lingüística no debería confundir, según el profesor suizo, la función con el soporte sonoro, como no lo hace tampoco el hablante, que sabe diferenciar, aunque no utilice un metalenguaje académico, el sustantivo casa y la tercera persona del verbo casar, a pesar de que se escriban y se pronuncien igual.

6. Acerca del pasaje de la episteme medieval a la moderna como abandono del orden de las semejanzas, se consultará, desde luego, el libro de Michel Foucault: Les mots et les choses, Paris, Gallimard, 1966. De esto se infiere que la tesis de la arbitrariedad del signo es una exigencia de cientificidad: abandonar las semcjanzas y las discmcjanzas cn favor de las identidades y las diferencias ( $\mathrm{y}$ en el estructuralismo la identidad resulta indisociable de las diferencias u oposiciones). En este aspecto, el abandono del orden mimético del pseudos vuelve a la vieja crítica platónica de la mímesis que suponía, entre otras cosas, la condena de la poesía. Y recordemos que en griego pseudos significaba mentira, falsedad, embuste, engaño, fraude, disimulo, trampa, añagaza, treta o ardid, pero también invención poética y ficción. 
Pero la poesía florece en el terreno de estas semejanzas azarosas o accidentales, de esta (auto)ficcionalización de la lengua. Así, en "Hay que buscarlo», Girondo acuña la «neovoz» aola (19) ${ }^{7}$ gracias a la verbalización del sustantivo ola por la adjunción del prefijo /a-/, pero también por la homofonía fortuita entre el morfema de género /-a / y el de conjugación de tercera persona $/-\mathrm{a} /{ }^{8}$. Algo comparable sucede en el tercer verso del poema "La mezcla» al que se refería Molina: "los ebrios lechos légamos telúricos entre fanales senos» (7). Ya tendremos la oportunidad de analizar con más detalle este verso, de una notable complejidad semántica y fónica, pero nos interesa por ahora una sola cuestión: así como los núcleos lechos y légamos son modificados por ebrios y telúricos, sería de esperar, siguiendo el paralelismo sintáctico y rítmico, que lo mismo ocurriera con senos; el significante fanales tiene, en efecto, una terminación que imita el plural del morfema adjetival /-al/común a estatales, racionales u originales; no se trata, sin embargo, de un adjetivo sino de uno de esos sustantivos del español terminados en /-al/, como tamal o canal, de manera que Girondo explota aquí la homofonía contingente con el susodicho morfema para simular o fingir una estructura de modificador directo más núcleo semejante a las dos anteriores -cuando se trata esta vez de una de esas metáforas por yuxtaposición de sustantivos estudiadas por Hugo Friedrich ${ }^{9}$. Digamos entonces que el poeta mezcla deliberadamente en sus versos los estratos que el lingüista se preocupa por distinguir en su disciplina, y que lo hace por mimetismo fónico.

Cuando nos introducimos en el dominio de los lexemas, los ejemplos se multiplican. Pero consideremos por ahora un caso sencillo. Girondo promueve en "Habría» una vecindad entre los significantes vicios y novicios (65). Se trata de una etimología apócrifa o ficticia, de una, digamos, seudoetimología: la sílaba /no/ simula una negación mientras que el segmento fónico /vicios/finge ser, por homofonía, el significante vicios, o se hace pasar miméticamente por él. Ahora bien, ¿cómo podríamos llamar a este segmento fónico? Ya no se trata de un lexema, aunque lo imite, ya no se trata tampoco de un morfema, aunque también simule un plural masculino,

7. Los números entre paréntesis corresponderán siempre a la página de la sexta edición de En la masmédula, Buenos Aires, Losada, 1997 (primera edición: 1956). En todos los casos, las itálicas nos pertenecen.

8. A lo cual habría que añadir en este caso una paronomasia entre aola y ahora, de modo que el verso "y aola aola aola" compara el paso del tiempo con las ondulaciones del mar.

9. Hugo Friedrich, Structure de la poésie moderne, Paris, Le Livre de Poche, 1999, p. 304. 
y si bien está compuesto de fonemas, no podemos sostener que sea uno de ellos. Retomando un viejo vocablo griego, podríamos denominarlos mimemas. $\mathrm{Y}$ es en este aspecto que ya no podemos hablar solamente de homofonía sino, además, de mimofonía, dado que nos encontramos ante una similitud que produce efectos de sentido: los novicios serían aquí quienes carecen de vicios. Y lo mismo ocurre más adelante, en este poema, con el verso: "volver a ver reverdecer la fe de ser» (66). El significante reverdecer, en efecto, puede descomponerse por homofonía en re-ver de (volver a ver, a tratar o a intentar de) ser, de modo que el sentido de todo el verso se concentra en esa sola palabra, como si ella se incluyera a sí misma en su propia definición (tratar o intentar algo supone una cierta fe en conseguirlo) ${ }^{10}$. Así como en español hay palabras compuestas por varios lexemas (soliloquio, noctivago, machimbre, etc.), reverdecer es una palabra compuesta por varios mimemas que imitan otras palabras de la lengua. De ahí que también pueda sostenerse que estos vocablos se encuentran mimetizados en el primero, en el sentido en que, proustianamente, Starobinski intitulaba Palabras bajo las palabras los manuscritos de Saussure sobre los anagramas ${ }^{11}$.

Cuando un estructuralista como Roman Jakobson afirmaba, a propósito de la función poética del lenguaje, que «toda similaridad aparente en el sonido será evaluada en términos de similaridad y/o disimilaridad en el sentido» ${ }^{12}$, ya estaba haciendo alusión a este fenómeno de mimofonía. Porque se habrá notado que el adjetivo «aparente», adosado aquí a «similaridad», se puede considerar en este enunciado como un sinónimo de fortuita o accidental. Pero el recaudo del maestro ruso resultaba, en última instancia, superfluo: si no se tratase de una «similaridad aparente», se trataría del mismo lexema o del mismo morfema. Ya no habría similitud sino identidad. Ya no se trataría de una imitación sino del original. De modo que Jakobson se está refiriendo a una asociación análoga a la que Saussure propusiera con el cuarto paradigma del esquema del Curso. Un seudo-paradigma morfológico que podría ser también, en otros casos, una seudo-serie léxica. $O$ si se prefiere, una serie seudo-léxica o seudo-morfológica, ya que no deja de ser un paradigma aunque se trate de una imitación por homofonía. Serie mimofónica, entonces. Cuando Jakobson afirmaba que «la función poética

10. Cabe recordar aquí que en el sistema fonético del geolecto rioplatense no hay diferencia entre $/ \mathrm{s} /, / \mathrm{z} / \mathrm{y} / \mathrm{c} /$.

11. Jean Starobinski, Les mots sous les mots. Les anagrammes de Ferdinand de Saussure, Paris, Gallimard, 1974.

12. Roman Jakobson, Essais de linguistique générale, Paris, Minuit, 2003, p. 240. 
proyecta el principio de equivalencia del eje de la selección al eje de la combinación" promoviendo así esta equivalencia "al rango de procedimiento constitutivo de la secuencia" ${ }^{13}$, estaba aludiendo a aquellas "similaridades aparentes», a esas seudo-equivalencias o a esos mimemas. Valen igual pero en el sentido en que la moneda falsa vale tanto como la genuina. $Y$ basta con evocar algunos de los ejemplos que Jakobson proponía en aquella conferencia crucial de finales de los años cincuenta para verificar que tenía en mente esas remotivaciones por homofonía. Que raven sea un anagrama de never, como señala a propósito del célebre poema de Poe, que Ike rime oportunamente con like, en el slogan de la campaña presidencial de Eisenhower, o que la expresión l'affreux Alfred parezca más adecuada que le dégồtant o l'insupportable Alfred, debido a la homofonía parcial entre epíteto y nombre, y al efecto de anominación que este encuentro produce, son azares con los cuales la lingüística ya no tiene nada que hacer. Ya Mallarmé sabía que la poesía se nutre de estos azares, y mejor aún: que ella misma es el azar de la lengua. Pero también que el azar tiene que ver con repeticiones que ya no obedecen a una única ley, o que no se confunden con dos o más casos particulares de una generalidad, y que, por este motivo, se sustraen a la ciencia ${ }^{14}$.

Tras las huellas de Mallarmé, la poesía del siglo XX explotará, de diversas maneras, el dominio de estos prodigiosos azares, y Girondo no será la excepción a la regla. Que el procedimiento preponderante sea, en los poemas de En la masmédula, el inventario, la enumeración o el catálogo, no

13. R. Jakobson, op. cit., p. 220.

14. De ahí que el acercamiento propuesto por Lacan entre el Saussure del Curso y el Freud de la Psicopatología o El Chiste haya resultado siempre problemático, por no decir paradójico, ya que el psicoanalista vienés se situaba precisamente en ese dominio de las homofonías, los retruécanos y los calembours que el lingüista suizo expulsaba de su disciplina como contingencias fónicas irrelevantes. El propio Lacan deberá aceptar, en su homenaje a Jakobson de 1972, que él no estaba haciendo lingüística sino «lingüistería» (linguisterie). Y será precisamente esta distinción la que lo llevará a acuñar, a través de una proclisis de la langue del Curso, el neologismo lalangue (lalengua), señalando así la diferencia entre el significante freudiano y el saussuriano, y extendiendo a cualquier palabra subjetivada esa relación entre los sonidos y los sentidos que el maestro ruso reservaba a la función poética del lenguaje. $C f$. Jacques Lacan, "A Jakobson» in Encore, Paris, Seuil, 1975, p. 24. A propósito de esto, un lingüista lacaniano como Jean-Claude Milner va a comentar: On comprend ia place singulière que chez Saussure occupe la théorie du paradigmatique: c'est le point critique où la langue est arrachée à lalangue, certaines associations seulement étant retenues, les autres étant désormais vouées à excéder le représentable et à subsister comme refoulées dans la forme d'un savoir inconscient. Jean-Claude Milner, L'amour de la langue, Paris, Seuil, 1978, p. 105.

14 R. Jakobson, op. cit., p. 220. 
debería pues extrañarnos. Un catálogo es el despliegue de un paradigma, la serie convertida en secuencia. Para que catálogo haya, los elementos que lo componen deben tener un rasgo en común, un componente que se repite. Pero esta vez los catálogos se construirán no sólo a partir de los rasgos sémicos comunes de las unidades enumeradas sino también, y por sobre todo, a partir de aquellas «similitudes aparentes» en el plano acústico, aquellas coincidencias fónicas contingentes -el catálogo se construirá, en fin, por mimofonía. La tesis de Jakobson según la cual la función poética consiste en el despliegue del paradigma en el sintagma podría reformularse diciendo que en el lenguaje poético la secuencia se construye por automimetismo, porque las correspondencias fónicas entre diferentes significantes pueden considerarse ahora como mimemas.

\section{2. "...LA MEZCLA CON QUE ADHERI MIS PUENTES..."}

Ironizando acerca de las metáforas de la vanguardia, frecuentadas por él mismo en su juventud ultraísta, Borges afirmaba que se habían dedicado a "correlacionar lejanías», o a asociar palabras de campos semánticos heterogéneos. Pero el lugar en donde se encontrarán el paraguas y la máquina de coser ya no será, en los poemas de En la masmédula, una mesa de operaciones sino la dimensión (eu)fónica de la palabra poética: las mimofonías ${ }^{15}$. De hecho, una metáfora por yuxtaposición de sustantivos pertenecientes a paradigmas heterotópicos, como la mencionada fanales senos, parece en este libro un sobreviviente de la época de los Veinte poemas o de Calcomanias. Y aunque no esté ausente, la metáfora ya no será la figura privilegiada por Girondo para establecer "puentes» entre las palabras, para

15. Tras recordar la "enciclopedia china" de "El idioma analítico de John Wilkins" de Borges, y compararla con la episteme medieval o el orden de las semejanzas, Foucault escribía: On sait ce qu'il y a de déconcertant dans la proximité des extrêmes ou tout bonnement dans le voisinage soudain des choses sans rapport; l'énumération qui les entrechoque possède à elle seule un pouvoir d'enchantement: 'Je ne suis plus à jeun, dit Eusthènes. Pour tout ce jourd'bui, seront en sûreté de ma salive: Aspics, Amphisbènes, Anerudutes, Abedessimons, Alarthraz, Ammobates, Apinaos, Alatrabans, Aractes, Asterions, Alcharates, Arges, Araines, Ascalabes, Attelabes, Ascalabotes, Aemorrö̈des...' Mais tous ces vers et serpents, tous ces êtres de pourriture et de viscosité grouillent, comme les syllabes qui les nomment, dans la salive d'Eusthènes: c'est là que tous on leur lieu commun, comme sur la table d'opération le parapluie et la machine à coudre... Michel Foucault, op. cit., p. 9. 
conectar o almohadillar ${ }^{16}$ paradigmas semánticos distantes de la lengua española. Estos puentes se «adhieren» («la mezcla con que adherí mis puentes» [8]) de diversas maneras, y estas mezclas serán de diversos tipos, comenzando por la formación de palabras-valija o "grifosones" (18), pero también neologismos o «neovoces» (30).

Uno de los méritos de estos conceptos consiste en ser autodescriptivos: la palabra neovoces es una neovoz, un término nuevo formado por la adjunción de un prefijo o, eventualmente, un sufijo español a un vocablo de esta misma lengua, como sucede con subósculos o trasueños; la palabra grifosones es un grifosón, un vocablo formado por condensación o mezcla de dos o más significantes -a la manera del célebre famillionariamente de Freudcomo sucede con aridandantemente, arpegialibaraña o olavecabracobra. Tanto los unos como los otros establecen entonces un vínculo in praesentia entre sus componentes, pero éste puede ser también in absentia. Así el grifosón almamasa (8), que aparece hacia el final de "La mezcla», se construye no sólo por condensación de alma y masa, y gracias a la repetición de la sílaba $/ m a /$, sino también por mimofonía (paronomasia) del sustantivo argamasa, asociación corroborada por su sinonimia, en la correspondiente secuencia, con una mezcla adhesiva. En este aspecto, el almamasa no será tanto la masa del alma como una argamasa psíquica encargada de "adherir» elementos generalmente distantes, establecer "puentes» entre series semánticas alejadas. Un grifosón conecta entonces dos campos semánticos diferentes, e incluso tres, si se toma en cuenta el significante que sirve de modelo para su formación, el significante imitado que, aunque latente, no deja de operar semánticamente en la secuencia. Así en el quinto verso de este mismo poema, Girondo forja el grifosón solicroo (7) por sustitución del lexema loquio en el sustantivo compuesto soliloquio. Esta sustitución, sin embargo, supone la conservación tácita del significante caído. Y esto se confirma porque a continuación va a insertar otra neovoz, las prefugas (7), en alusión a esas composiciones elaboradas a partir de una superposición de voces melódicas, mientras que en el décimo verso este paradigma musical se prolongará en la secuencia: «los acordes abismos de los órganos sacros del orgasmo" (8).

16. El lacanismo hispanoparlante ya aceptó este verbo para traducir el acto de capitonnage al cual se refería Lacan a propósito de los lapsus o las metáforas. J. Lacan, Ecrits, Paris, Seuil, 1966. 
Girondo pone en práctica un procedimiento similar a propósito del grifosón noctivozmusgo que abre el poema "Gristenia»:

Noctivozmusgo insomne

del yo más yo refluido a la gris ya desierta tan médano evidencia (43)

Este grifosón se constituye a partir del adjetivo poético noctívago, que es una palabra compuesta como lo era ya soliloquio. Los significantes voz y musgo se añaden por homofonía parcial con vago $(v, g o)$ que se convierte esta vez en el elemento sustituido. Pero Noctivozmusgo es un verbo en primera persona que imita, podría decirse, la conjugación de primera persona del presente del verbo juzgar. Insomne, a su vez, funciona como un complemento circunstancial de manera que pertenece al paradigma semántico del adjetivo noctívago. $\mathrm{Y}$ aunque el término vago haya sido suprimido del aquel grifosón, se conserva como un componente latente, o vuelve como lo reprimido, ya que el segundo verso supone un desplazamiento "de... a...» que semánticamente no está implícito ni en lo nocturno, ni en la voz, ni, desde luego, en el musgo.

Podemos mencionar algunas ocurrencias similares sin elaborar aquí un listado exhaustivo. Así en "Al gravitar rotando" la neovoz bisueño (11) es una paronomasia de risueño y retrospectivamente también remotiva la palabra imitada, como si una persona riente fuera también soñadora. Entreasco (66) se construye a partir del sustantivo entreacto, mientras que la neovoz amente (12) se forja por epentesis del significante amante pero sigue el mismo principio constructivo que la palabra demente. Esta asociación va a confirmarse cuando en "Balaúa» Girondo escriba: «en el la maramor I plenamente amada» (60), un verso en el cual el adverbio plenamente reúne los mimemas de pleamar, amar y amante. Pero el poeta ya había establecido una asociación semejante cuando en "Hasta morirla» hablaba del "amormor pleamante» (45).

Insistiendo con el mismo procedimiento, la neovoz Amustios (14), privación del adjetivo plural mustios, se emparienta fonéticamente con angustias, mientras que el grifosón ascuacanes (13) pareciera haber sido acuñado por homofonía con el sustantivo astracanes. Girondo inventa el verbo antepudiese (22) por su paronomasia con antepusiese, o covaciarse (21) por su analogía con congraciarse. El adjetivo contelúricos (13) parece un lapsus linguae de contertulios, erosismos (25) de erotismos, coyoes (66) de coyotes, desinhalar (32) de deshilvanar, desalmes de desarmes, malentetando (58) de malentendiendo, mascaduda (59) de mascadura, masturbio (35) de masturbo, traspienso (69) de traspié, mientras que cogitabundo (53) y 
dubitabundo (58) se elaboran por analogía con meditabundo, término que pareciera subyacer a su vez en el grifosón meditaturbio (31). Gociferando (12) es un grifosón que imita el gerundio vociferando y grislumbres (9) es una deformación de vislumbres. Musaslianas (12) establece un puente semántico entre Musas y lianas, pero también, por paronomasia, o mimofonía, entre las musarañas y las muselinas, mientras que gristenia (43) une el color gris con el gusano llamado tenia, pero simula un parentezco con la astenia y también, acaso, la histeria. Mastoco (42) es evidentemente una yuxtaposición del adverbio más y el verbo toco, pero también una epentesis del verbo mastico, del mismo modo que nubecosa (17) lo es del sustantivo mucosa. Nonadas (57) reúne en un sustantivo plural el no y la nada pero remite al significante monadas, al tiempo que lo remotiva. Esto ocurre también con los gerundios yollando y yoyollando (51) en "Yolleo" enteramente forjados a partir de su homofonía con llorando y sollozando, y que al mismo tiempo remotivan ambos verbos como si sendas sílabas $/ l l o /$, convertidas en mimemas, provinieran de los pronombres de primera persona ${ }^{17}$.

Como sostiene en un trabajo reciente Jean-Jacques Lecercle, las palabrasvalija «niegan lo arbitrario del signo inyectando motivación por todas partes» ${ }^{18}$, induciéndonos a buscar "palabras bajo las palabras». O traduciendo este enunciado según nuestro léxico: los grifosones nos invitan a descomponer las palabras del diccionario en mimemas. Así los vocablos que supuestamente pertenecen a una única especie comienzan a revelarse como grifones, quimeras o esfinges significantes, y aquellos, presuntamente puros, o con un linaje etimológico bien atestado, confiesan una bastaría imprevista. Pero ya Michel Leiris sostenía que si existen palabras-valijas, existen también "palabras desvalijadas» (mot dévalisés) ${ }^{19}$, como era el caso, en Girondo, de

17. Se recordará aquí que en el español rioplatense tanto la /y/ como la /ll/ se pronuncian como una fricativa alveolar sorda, a la manera de la $/ \mathrm{x} /$ catalana o la $/ \mathrm{ch} /$ francesa.

18. Jean-Jacques Lecercle, La violence du langage, Paris, PUF, 1996, p. 94. Lecercle recuerda en este libro a Jean-Pierre Brisset (1837-1923) «lingüísta delirante, autor de La Gramática lógica y de La Ciencia de Dios, descubierto por Breton y redescubierto por Foucault [...] célebre por haber tratado de probar, por medios puramente filológicos: que el hombre desciende de la rana» (p. 68). Brisset pertenece al linaje de Varron e Isidoro de Sevilla y puede considerarse como un precursor de Michel Leiris pero también de Oliverio Girondo. Acerca de las palabras-valija en Lewis Carroll se consultará también el imprescindible trabajo de Gilles Deleuze: Logique du sens, Paris, Minuit, 1969.

19. Leiris proponía en su Glossaire las siguientes ocurrencias. sangloter: ôter ses sangles; foudre: le feu en poudre; décimer: détruire les cimes; abrupt: apre et brut. Citado por Bernard Dupriez, "Remotivación» in Gradus. Les procédés littéraires (Dictionnaire), Paris, 10/18, 1984, pp. 393-394. 
los citados reverdecer y novicios. Así en el tercer verso del mencionado poema «La mezcla», el sintagma «los ebrios lechos» (7) podía leerse como una hipálage (ebrios están los amantes en el lecho de amor) pero también como una remotivación, o la revelación de un mimema, en el adjetivo ebrios por su asociación con los lechos de los ríos: eb rios. Algo similar ocurre en «Porque me cree su perro" cuando Girondo escribe: «toda su gris resaca me sacaré hasta el meollo" (69), en donde el sustantivo resaca se ve remotivado por su vecindad con el verbo me sacaré, convertido en su mimofonía enclítica. Otro ejemplo de este procedimiento puede encontrarse en "Topatumba», una formidable recreación poética del acto sexual, cuando Girondo escribe:

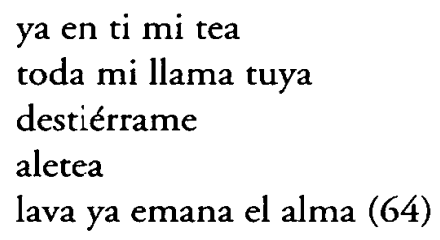

El imperativo aletea se convierte aquí, por la cercanía del sustantivo tea y por asociación semántica con la llama, en una suerte de grifosón, mezcla de los mimemas de ala y tea, asociación corroborada por el hecho de que se trata de la agitación febril que precede al orgasmo. A esta misma remotivación por combinación de dos significantes homofónicos recurre Girondo en "Maspleonasmo" al escribir: "y mago rapto enlabio de alba albatros» (35). Nada menos que un ave baudelairiana como el albatros se ve convertida en un pájaro del alba, e incluso en un alba atroz. Y lo mismo ocurre en «Habría» con el verso: «un mero medio huevo al menos de algo nuevo» (65). La rima o la homofonía parcial entre huevo y nuevo remotiva recíprocamente ambos significantes, como si el huevo fuera lo que encierra lo nuevo, o como si lo nuevo fuese lo que se halla en un huevo. Este mismo efecto mimofónico se produce cuando en «Soplosorbos» Girondo escribe: «Solo tumbos / retumbos» (48), y convierte así las resonancias en caídas reiteradas, o las propias caídas, si se prefiere, en sonidos o ecos. Así en "La mezcla» la expresión «rito negro» (8) va a revelar la existencia del mimema ritos en el diminutivo suspiritos que aparece a continuación y que rimará luego con el adjetivo fortuitos. Este efecto mimofónico se reitera en "Habría" cuando Girondo escribe: «e inmerso en el subyo intimísimo" (65). Imitando el pronombre $m i$, y una suerte de condensación de mímismo, los mimemas mí y mis(i)mo se ponen en evidencia en el superlativo intimisimo gracias a la proximidad de la neovoz subyo. 
Pero a lo largo de En la masmédula abundan los juegos de palabras con los pronombres de primera persona. Un caso notable es el sustantivo cobayo en la primera de las «Posnotaciones»: "Yo cobayo de altura» (52). La repetición de la sílaba /yo/ remotiva el primer sustantivo como si fuera una mezcla, o un grifosón, formado por los mimemas /coba/ (que imita el término coba, sinónimo de broma o embuste) y $/ y o /$ (que finge ser un pronombre de primera persona). Pero algo semejante sucede en algunos versos de "Tantan yo»: "con mi yo en mí / yo mínimo", "yo abismillo» (67) o "nada yogui» (68). Y este juego con el pronombre de primera persona se encontraba ya en los dos primeros versos de este poema:

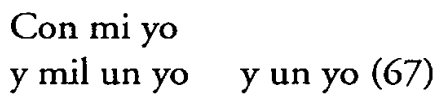

Así el numeral mil aparece como una palabra cuya raíz sería el adjetivo posesivo $m i$. Y cuando más abajo Girondo hable del "posyo del mico ancestro...» (68), en alusión al origen simiesco del hombre, volveremos a encontrar aquel adjetivo posesivo en un mimema del significante mico. La conjunción "taté teté yo y lamì (69) de "Porque me cree su perro" genera un efecto mimofónico similar, o incluso el verso «ni yo ni fosa ni hoyo» (28) de "El puro no", en el cual podría definirse el término hoyo, a la manera isidoriana o leirisiana, como la fosa del yo. Aunque se trata en términos estrictos de un grifosón, el título "Mi lumía» (33) supone una operación semejante: la sílaba /mi/del lexema /lumi-/, presente en luminoso, lumínico o luminiscencia, se convierte, por influencia del adjetivo posesivo $m i$, en un mimema del pronombre mía.

Estas mimofonías pueden dar lugar a criptogramas como el que Girondo propone en el poema "Soplosorbos»: "el veneno de almendras que se expande al destapar un seno" (48). Si nos limitáramos a la dimensión imaginaria del verso, la escena sería -digámoslo así- surrealista: una mujer descubriría su seno y de él se desprendería un veneno hecho de almendras. Pero cualquier lector de novelas policiales sabe que el veneno con olor a almendras es el arsénico y que el seno en cuestión se encuentra mimetizado en este significante: arsénico. Así la palabra arsénico se remotiva como si la raíz griega /ar-/, presente en vocablos del español como aroma, y el morfema adjetival /-ico/, a la manera de aromático o artístico, hubieran sido añadidos al lexema /sen-\%. Pero una versión más sencilla de estos criptogramas podemos hallarla en el segundo verso de "El pentotal a qué» en donde el 
artículo femenino se convierte en un mimema de la sexta nota de la escala musical: «el consonar a qué la sexta nota» (25).

Como vimos a propósito del ejemplo de raven y never evocado por Jakobson en su lectura de Poe, un grifosón también puede formarse como un anagrama de otro significante. Así el término erolocas, mezcla de los mimemas eros y locas, incluye un anagrama de corolas, y esto explica por qué puede convertise en su adjetivo como en el séptimo verso de "Aridandantemente»: "junto a tan tantas concas corolas erolocas" (15). El nombre de las coronas que rodean los órganos de reproducción de las flores, cuya etimología proviene del latín corolla (vale decir, coronilla), se ve remotivado en este sintagma como si aludiera a una sexualidad delirante -0 como si toda sexualidad, en cierto modo, lo fuera.

Un grifosón puede condensar también dos significantes que sean mutuamente anagramas, y es lo que sucede con la ocurrencia ecosecos (30) en "Rada anímica", mezcla de ecos y secos. Hay también un anagrama criptográfico en "Habría» que sólo puede descifrarse si se lo sitúa en la secuencia correspondiente:

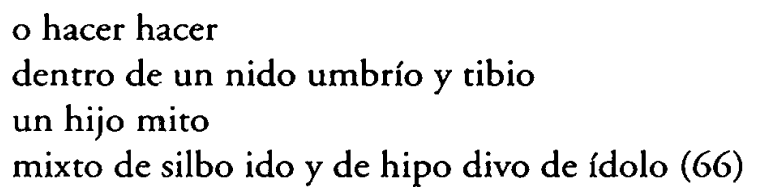

El «nido umbrío y tibio» dentro del cual se hará el «hijo mito» es sin duda el vientre materno. Y el mito del hijo por excelencia, "mixto... de hipo dìvo", es el mito de Edipo. Pero además la palabra silbido se ve en este verso remotivada como si se tratase de un silbo que ya se fue. Lo mismo ocurre al final del verso con el sustantivo ídolo, convertido, por mimofonía, en la enclisis de la expresión lo ido. Y esto sin contar con que la vecindad entre mito y mixto remotiva sendos vocablos.

Este procedimiento lo encontramos también a propósito de dos lejanías correlacionadas en el poema "Alta noche», cuya asociación, sin embargo, no nos suena arbitraria en una primera lectura sin que sepamos muy bien por qué: "huracanados rostros» (37). Mucho más que en el caso de aquellos senos que despedían ponzoña, resulta difícil imaginarse cómo serían estos rostros huracanados. Pero como decía Freud a propósito de los sueños, no debemos intentar resolverlos interrogándonos acerca de la significación de las imágenes evocadas sino de los jeroglíficos formados por ambos significantes ${ }^{20}$. En el adjetivo huracanados se mimetiza esta vez un anagrama de

20. Sigmund Freud, La interpretación de los sueños II, Barcelona, Planeta-Agostini, 1985, p. 307. 
cara, de modo que la combinación "huracanados rostros» sigue el principio de la función poética propuesto por Jakobson: despliegue del eje de las sustituciones en el de las combinaciones. Sólo que el encuentro entre ambos significantes hubo de tener efectivamente lugar para que el sustantivo rostro revelase retrospectivamente el anagrama de cara en su inusual adjetivo. De igual modo, Girondo escoge el adjetivo afrodisiaco para calificar al "rocío" de la «voraz contráctil prensil corola entreabierta» (75), porque la palabra rocío se encuentra diseminada en afrodisíaco -o porque afrodisíaco contiene un mimema diseminado del significante rocío.

Como sucedía con los grifosones, este tipo de asociaciones puede ser también in absentia. Así en este mismo verso la combinación «de subsueños de cauces» (37) se vuelve posible porque la neovoz subsueños se armó por paronomasia con la palabra subsuelos (cauce: subsuelo del río). El verso «las idóneas exnúbiles» (26) se construyó por similicadencia con la expresión «los idiotas útiles», mientras que «inferneos en familia» sustituye, imita y remotiva "veraneos en familia", del mismo modo que "circuitos ahogados" (30) rima con la expresión "circuitos cerrados" y "ascua viva" (73) con «aguaviva» (o medusa en Argentina).

A las mimofonías paronomásticas y anagramáticas podemos sumarles entonces los metanálisis, una figura que invierte, en muchos casos, la operación de síntesis que da lugar a grifosones y neovoces. Ya en el séptimo verso del poema "La mezcla» leemos la ocurrencia «lo impar ido» (7) en la cual el pasado del verbo ir imita un morfema de participio pasado "adherido", como diría Girondo, al verbo parir, hasta el punto de invertir el sentido del verso: lo imparido. También hallamos dos metanálisis semejantes en «Mi lumía»: «mi mito» (mimito) y «mi pez hada» (mi pesada) (34). Y tres en "Tantan yo»: «yo ralo» (lloralo), "yo voz mito" (yo vomito) y «sin mí ni yo» ( $\sin$ miniyo) (68). Hasta que Girondo llegue al metanálisis de su propio nombre en «Hasta morirla»: «y su giro hondo..." (46).

Pero los metanálisis pueden operar por descomposición de un vocablo usual. Esto ocurre ya con el título «El uno nones» (23) que puede leerse, por mimofonía, como el uno non es, frase que va en el sentido de lo que afirmará a continuación el poema. En uno de sus versos Girondo escribe además "tornasol lamido" (24), combinación inusual desde una perspectiva semántica, aunque no se trate de un sinsentido, pero que se revela como una suerte de criptograma cuando descubrimos que las sílabas se convierten en los mimemas de cuatro notas musicales: (torna) sol, la, mi, do. Y ya Girondo había propuesto el metanálisis inverso en «El pentotal a qué» cuando escribió: «el re la mí sin fin» (el relamí sin fin) (26). 
Siguiendo un principio similar, Girondo propone en "Gristenia" la secuencia «...a la gris ya desierta tan médano evidencia» (43). Que la palabra médano provenga, por sinécdoque, del desierto evocado a través del adjetivo femenino desierta, no cabe la menor duda. Pero resulta difícil decir de dónde proviene el significante evidencia cuando de desiertos se trata. Tenemos en primer lugar el adjetivo gris que califica a evidencia, y en el sintagma evidencia gris resuena, por similicadencia, la expresión eminencia gris. Pero la clave de este criptograma se encuentra en el metanálisis del adjetivo desierta, que también califica a evidencia, y que podemos descomponer en los mimemas de cierta. Así obtenemos el sintagma de cierta... evidencia, de modo que el sustantivo médano revela un parentezco apócrifo con mediana o mediocre: de cierta tan mediocre evidencia. Del mismo modo, nos preguntamos por qué "Alta noche» comienza con este verso enigmático: "De vértices quemados» (37). Al igual que el "tornasol lamido", no se dirá que estemos ante un sinsentido, y sin embargo no podemos dejar de interrogarnos acerca de su significación. Pero el enigma se resuelve gracias a un metanálisis de la cadena: de ver tizos quemados, de manera que el adjetivo quemados se obtiene aquí por sinécdoque del mimema del sustantivo tizos.

\section{3. “...EL INTRAFONDO EUFONICO...”}

Estos primeros versos del poema «Alta noche» nos permiten pasar entonces a ese otro tipo de mimemas, o "subvoces», que son los ecos sonoros $^{21}$. Así en el mencionado segundo verso de este poema encontramos la secuencia "de cauces de preausencia" (37) en la cual se repite el segmento fónico lausel, mientras que el cuarto verso se constituye a partir de la reiteración de la partícula /ral: «de soterráneas ráfagas de ratas de trasfiebre invadida» (37). Esto volverá a ocurrir en «Por vocación de dado»: "ho ra tras otra lacra...» (32). O, en el mismo poema, con el mimema /cop/: «y sincopar la cópula» (32). Incluso los ecos sonoros pueden darse encadenados, con una

21. En diferentes oportunidades Henri Meschonnic propone englobar las rimas, las aliteraciones y las asonancias bajo la categoría de eco con el fin de no separar la dimensión fónica y la semántica del poema y evitar así la escisión clásica entre la forma y el contenido. A nosotros nos parece que podemos mantener la terminología tradicional, respetando la exigencia de Meschonnic, en la medida en que todos estos fenómenos de homofonía se consideren como mimemas. Ver H. Meschonnic, Pour la poétique I, Paris, Gallimard, 1970; Gérard Dessons et Henri Meschonnic, Traité du rythme, Paris, Dunod, 1998. 
palabra que sirva de "puente" mimético para pasar de uno a otro, como sucede con la secuencia: «sin lastre sin máscara de espera» (32).

Siempre habrá que tener en cuenta, en casos así, que dos bilabiales (b/p), dos dentales $(\mathrm{d} / \mathrm{t})$, dos guturales $(\mathrm{g} / \mathrm{k})$, dos líquidas $(\mathrm{r} / \mathrm{l})$ o dos nasales $(\mathrm{m} / \mathrm{n}$ ) son equivalentes cuando de ecos o rimas se trata, como sucede en el verso: "ausentes en seminal yacencia» (57). O en este otro, tomado de "Soplosorbos": "fofo hartazgo termita y asco verde" (48). Pero en este verso hay también un eco entre hartazgo y termita, y entre termita y vende (si es que no contamos esta última ocurrencia entre las metatesis, dada la equivalencia entre las consonantes dentales: termita y verde). Pero también en "Hasta morirla» podemos encontrar un mismo verso con dos ecos fónicos diferentes: "los dones dados donde se internieblan las órbitas los sorbos de la euforia" (45). Algo que ya sucedía en el quinto y sexto verso de "Alta noche»: "con su animal doliente cabellera de libido / su satélite angora" (37). Estas repeticiones pueden comportar incluso ciertas variaciones como en el verso "resurrecto resto de éste a aquello o de lo opuesto" (61) de «Destino». Girondo había propuesto una homofonía parcial semejante en el poema "La mezcla» con el sintagma "tensa las tercas hembras tuercas» (8), mientras que da lugar al verso "la estéril lela estela» (45) en "Hasta morirla», "rompientes del entonces» o "rompientes del entonces» (47) en "Soplosorbos», "que lindan con la infancia» (32) en "Por vocación de dado", "alga de algo» (67) en "Tantan yo», "Ay mi más mínimo mimo mío» (63) en «Topatumba", "sus vertientes lentas entremuertes» (75) en "Ella» y el calembour "creer en crear / y croar y croar» (66) en "Habría».

$\mathrm{El}$ eco sonoro ya se encontraba en el mencionado segundo verso de «La mezcla» («el fofo fondo»), pero también en el tercero: «los ebrios lechos légamos tehúricos entre fanales senos» (7). Sólo que aquí habría que tener en cuenta la metatesis de la sílaba /le/, a saber /el/, en el significante tehúricos. Esta inclusión de metatesis, inversiones o anagramas parciales como variante de los mimemas es muy corriente en los poemas de En la masmédula. Basta con recorrer los versos de "La mezcla" para dar con las siguientes ocurrencias: "el tacto incauto" (7), «los acordes abismos de los órganos sacros del orgasmo", "el rito negro... de gorriones", "la total mezcla» (8). O en "Canes más que finales», la secuencia: "pregárgolas sangrías / canes pluslagrimales... márgenes" (13). Y ya citamos un verso de "Maspleonasmo» con una metaresis notable: "y mago rapto en labio de alba albatros» (35). En "Tantan yo" una metatesis semejante va a combinarse con una homofonía total: "...en vilo ya lívido de líbido» (68), de manera que el significante vilo se encuentra mimetizado en lívido y líbido. 
Pero estos ecos invertidos, o anagramatizados, se multiplican a lo largo del libro (y la lista, una vez más, no se pretende exhaustiva): «por sus arpones rabos» (13), "que autonutre sus ecos de sumo experto en nada» (nutre-sumo, nutre-experto; y sin inversión: sus-sumo, ecos-eksperto) (23), «los refrotes fortuitos» (25), «los avernitos intimos» o «los avernitos íntimos» (26), «los hipertensos tantanes de impresencia» (29), "los ubicuos... circuitos» (30), los "elencos del asco», "de moviles carnívoros" o "más sacra came carmen» (35), "lacios salmos», "huésped sueño", "lorosimio implume», "ramos de sombras" (37), "desde ot ra arena oscura y otro ahora..." (38), "desde otra orilla prófuga» (38), "la gr is ya desierta tan médano evidencia» (43), "y su yo solo oscuro de pozo..." (43), "de la posnáusea obesa» (43), "de subsueños de cauces", "que arenan el ahora» (47), "esperas que lepran la espera» (48), "yo...oyes» (50) 22 , "sino inórbito asombro» (53), "todos los in termedios pudresientes de espera» (57), "carcomas diametrales" (57), "hueros logros de horas lagrimales / aunque el sabor no cambie», "para entregarse entero o de tres cuartos... al entrevero» (62), "...sempiterno de lo aparente» (62), "entremuertes que estrellan... vientre" (75), serie en la cual podríamos incluir un grifosón como «soplosorbos», o un título como "Porque me cree su perro» (or, $r k, k r, r e, e r, r o$ ), pero también una más amplia diseminación del mimema /co/o /go/como en «Ella»:

...molusco
que gota a gota agota boca a boca
la mucho mucho gozo
la muy total sofoco
la toda "shock" tras "shock"
la íntegra colapso
es un hermoso síncope con foso
un "cross" de amor pantera al plexo trópico
un "knock out" técnico dichoso (76)

Se notará además que en un verso como «los acordes abismos de los organos sacros del orgasmo" (8), la última palabra parece haberse formado

22. Esta metatesis del poema "Yolleo" pone en evidencia hasta qué punto este tipo de mimofonías se imponen por sobre la concordancia gramatical. En efecto, este poema comienza con un apóstrofe "Eh vos» (50), dirigido al «tatacombo" (Dios). El uso del roseo rioplatense hubiese exigido que Girondo escribiera «no me ois», variante que adopta luego cuando escribe «si sos» (51), y sin embargo el poeta privilegia la conjugación correspondiente al tureo, «oyes», para conservar la inversión fónica de "yo». 
por condensación de órganos y abismos. Y no será la última vez que Girondo recurra a este principio. Así en «Ella», el poeta escribe:

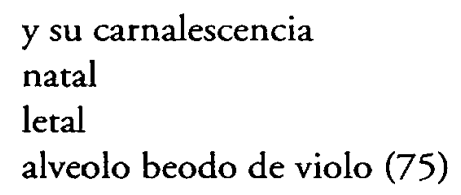

Girondo descompone el mimema /nale/ de carnalescencia en /nal, lall y / le/ y lo disemina en los siguientes significantes: natal, letal y alveolo. $\mathrm{Y}$ en este mismo poema hallamos el sintagma «inalada larva de la nada» (76), como si larva y nada se obtuvieran por descomposición de inalada. Una variante de este recurso podemos encontrarla también en el criptograma de "Soplosorbos» al cual ya hicimos alusión: "el veneno de almendras que se expande al destapar un seno" (48). Ya la palabra veneno repetía el mimema len/ que volveremos a hallar en almendras y en seno, mientras que la sílaba $/ \mathrm{se} / \mathrm{de}$ se expande, y su metatesis en destapar, se reitera, una vez más, en seno. $\mathrm{Y}$ esto sin contar la combinación "que se expande» en la cual observamos la repetición kes...eks. En aquellos versos de "Topatumba» que citamos más arriba podíamos verificar un procedimiento semejante para definir el orgasmo: «lava ya emana el alma» (64), como si alma se constituyera por una síntesis de la sílaba /la/de lava y la sílaba /ma/de emana.

Como sucederá en «Mi lumía» con la sílaba /lul, el grupo fónico /no/, incluida la variante $/ m o /$, pero también, por asociación semántica, los significantes $n i$, sin, nada, cero y el prefijo in- $o$ im-, va a verse diseminado a lo largo del poema «El puro no»:

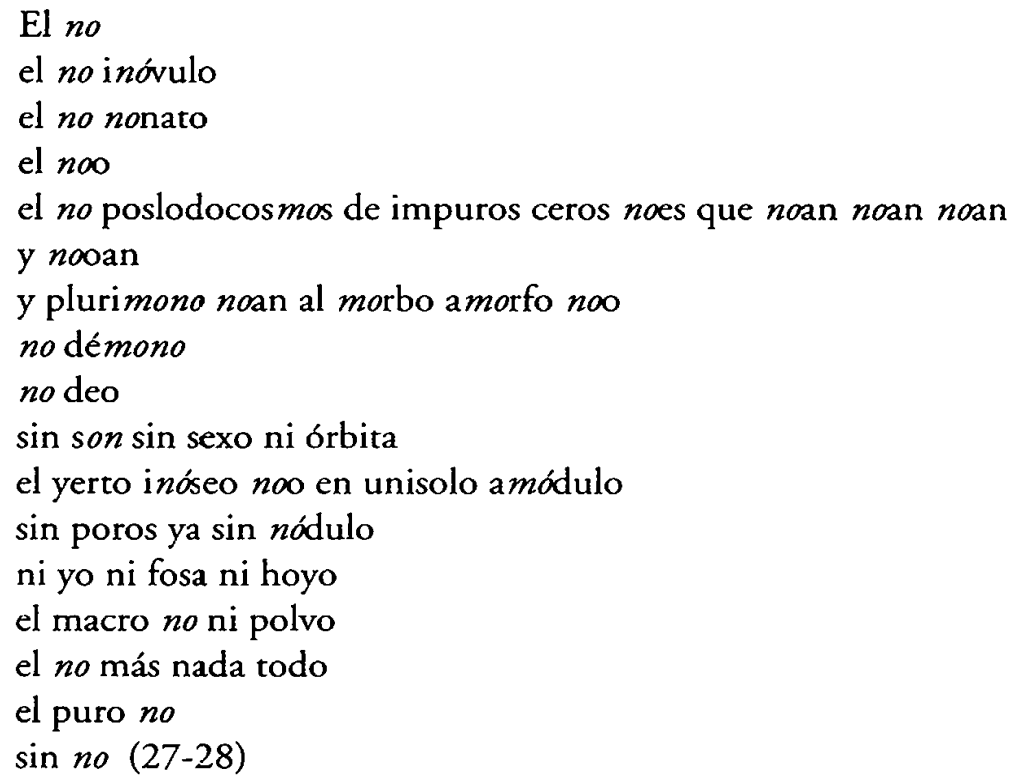


Al grupo de los ecos sonoros pertenecen también las rimas, como sucede en este poema con los términos hoyo, polvo y todo situadas al final de tres versos consecutivos, pero también con el ejemplo del «alveolo beodo de violo" que puede calificarse de psitaquismo, al igual que las ocurrencias "trago tardo largo" (69) (que propone también una metatesis de /ra/) y "obtuso yo zurdo absurdo burdo" (70) en "Porque me cree su perro" o el "lato amor gayo nato" (36) de "Maspleonasmo", un poema en el que, por otra parte, el propio Girondo se burla de este recurso: «más santo hartazgo grávido de papa rica rima de tanto lorosimio implume vaterripios» (36). Resulta sin embargo difícil establecer una distinción neta entre las rimas y los otros géneros de ecos sonoros, como ocurre al comienzo del poema "Al gravitar rotando":

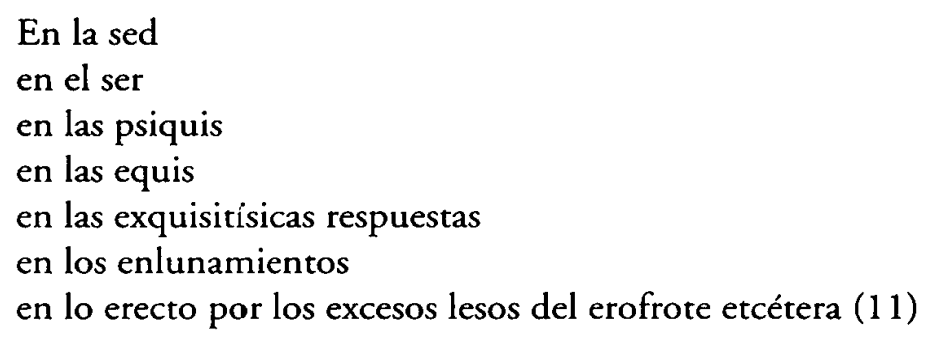

Tenemos por último, las asonancias y las aliteraciones como mimemas mínimos. Como lo señaló Enrique Molina, "La mezcla» comienza con una grave asonancia en /o/: "No sólo / el fofo fondo». Y así como la palabra de Molina imitaba esta asonancia, puede considerarse que las cadenas de aliteraciones y asonancias son automimofonías. Así, en el segundo verso de este poema va a alternar la asonancia en /o/ y la asonancia en /e/: «los ebrios lechos légamos telúricos entre fanales senos", mientras que en el siguiente verso de "Yolleo» predomina la /i/: «entre $\mathrm{m}$ is subyollitos $\tan \mathrm{n} i \mathrm{~m}$ ios $\mathrm{m} i$ cropsíquicos». Y para dar un ejemplo contundente de asonancia en /a/ que genera la secuencia por automimetismo, podemos recordar tres versos de "Rada anímica»:

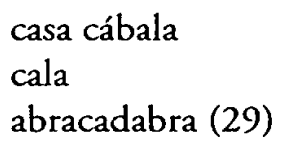

El tercer verso de "La mezcla" podía ser también un ejemplo de aliteración en $/ l /$, lo mismo que el vigésimo, en $/ m /$ : «la pura impura mezcla que me merma los machimbres el al mamasa tensa las tercas hembras tuercas" (8). En un título como "Islas sólo de sangre» (17) Girondo alterna la 
aliteración de las $/ s / y$ de las líquidas $(l, l, r . .$.$) . La ocurrencia "gris sangre»$ (37) en el tercer verso de "Alta noche» está construida como si fuera un tono de gris -como quien dice rojo carmesí o verde musgo-, pero ningún rasgo sémico nos permite asociar esta vez ambos términos sino un rasgo fónico repetido, /gr/, algo que ya en la expresión el grito de la sangre que seguramente no se hubiera convertido en un tópico sin el apoyo de la correspondiente aliteración. Lo mismo ocurre en ese verso cuando Girondo menciona los «complejos de niebla» (37) -verso que tiene su versión en metatesis: «los complejos velados» (26).

Ecos, metatesis, asonancias y aliteraciones pueden encontrase también combinadas para constituir uno o varios versos. Así "Noche totem» comienza diciendo: «Son los trasfondos otros de la in extremis médium» (9). La asonancia en $/ o /$ domina el primer hemistiquio, y en /e/ el segundo. Pero también tenemos una aliteración en $/ s / \mathrm{y}$ otra en $/ t r /$. Hay al menos un eco sonoro entre son y trasfondos, y finalmente tres metatesis: "Son los trasfondos otros», «la in extremis» e "in extremis médium». Y una combinación comparable da lugar a un verso de «Por vocación de dado»: «por puro pleno pánico de adherir a lo inmóvil del yacer sin orillas» (32).

\section{4. “...EL ALMAMASA TENSA..."}

A las series constituidas por mimofonía, o remotivación por homofonía, habría que añadirle, desde luego, las series estrictamente semánticas, siempre combinadas con las primeras, lo que da lugar a una suerte de sobredeterminación de cada significante, comparable con las cadenas de asociaciones analizadas por Freud en su Psicopatología ${ }^{23}$. Tomemos, a título de ejemplo, la primera de las dos estrofas del poema "Tropos»:

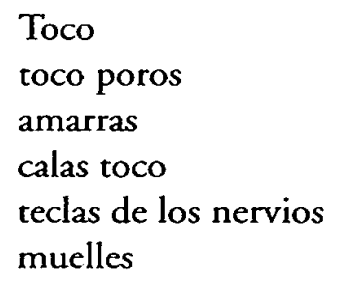

23. Recordemos el célebre caso de olvido de nombre propio con el que Freud abre su Psicopatologia de la vida cotidiana (Paris, Payot, 2001, pp. 8-14). Freud conversa con un compañero de viaje acerca de los frescos de la catedral de Orvieto, pero olvida el nombre de su autor, Signorelli, que él sustituye por los de dos artistas italianos: Botticelli y Boltraffio. Freud vincula la aparición de ambos nombres con sendos recuerdos: uno, acerca de los turcos de Bosnia-Herzegovina, que tiene relación con la muerte; otro, acerca de uno de sus pacientes, 


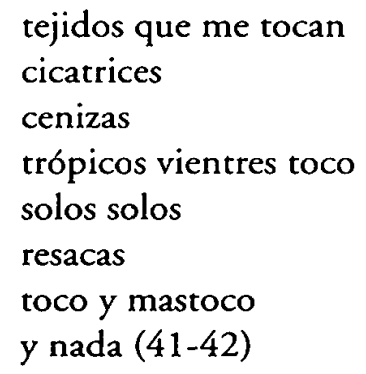

El poema comienza con una palabra, "toco", asociada, por asonancia o rima, con el significante del título: «Tropos». El segundo verso, "toco poros», abriga, a su vez, un mimema anagramático de tropos. Pero la serie «amarras», "calas», «muelles», que declina una isotopía portuaria o marítima, y que continuará con «resacas", es sugerida acaso por la asociación tocar puerto. La expresión tocar teclas explicaría la aparición de este sustantivo en el quinto verso, y si se trata de nervios, sería por paronomasia con un significante latente en la serie portuaria, navios, pero también, retrospectivamente, por la alusión implícita al plexo solar (red nerviosa que circunda la arteria aorta ventral) en el décimo verso. "Tejidos» surge de un eco sonoro de tedas, lo mismo que la voz "cicatrices», encargada de encadenar el verbo "tocan» con el sustantivo "cen izas». La combinación «trópicos vientres» está doblemente determinada. En primer lugar, por mimofonía entre tropos y trópicos (esta vez justificada etimológicamente) pero también por la mencionada expresión plexo solar que ya en "La mezcla» Girondo había convertido en "plexo trópico», por contigüidad semántica entre solar y trópico, asociación que Girondo debe haber considerado un hallazgo poque la volveremos a encontrar en «Ella»: «un 'cross' de amor pantera al plexo trópico» (76). «Solos solos», retoma, a continuación, la asonancia de «toco poros», y así como tenemos en el segundo y tercer verso la combinación «toco poros / amarras», Girondo propone aquí, por similicadencia, «solos solos / resacas». Pero estas resacas (movimiento de retroceso de las olas después de llegar a la orilla), nos permiten leer en ese «solos solos», por mimofonía, "olas olas», sucesión de ondas acuáticas ya mimada en el

de la ciudad de Trafoi, que se había suicidado a causa de sus problemas sexuales. El olvido de Signorelli está relacionado entonces con el significante italiano Signore, traducción del Herr alemán, cuyo eco fónico o mimema encontramos en Herzegovina. Botticelli proviene, a su vez, de dos ecos fónicos diferentes: la terminación /elli/de Signorelli y la sílaba /bo/de Bosnia. Y Boltraffio, por último, de tres, asociados con los significantes Bosnia y Trafoi, siendo el tercero un eco invertido o una metatesis: /fio/, /foi/. De manera que tenemos aquí tres casos de anominación, o remotivación de nombres propios, donde, para utilizar el léxico de Girondo, Signorelli, Botticelli y Boltraffio se revelan como "mezclas" o "grifosones". 
verso "y aola aola aola» (19) de "Hay que buscarlo». "Estertores», en este aspecto, parece estar, una vez más, triplemente determinado: por homofonía con resacas (estertores, resacas; estertores, resacas), por metatesis de tropos (estertores) y por paronomasia con estero (terreno bañado por las mareas).

Una combinación semejante de series semánticas y mimofónicas la encontrábamos en "La mezcla». El grifosón solicroo-que, como vimos, se construía a partir del vocablo soliloquio y proseguía la serie «líquida» de los ríos, los líquenes y la profusa aliteración en $/ 1 /$ - se encadenada con "las prefugas» (7) del sexto verso (loquio, voces, fugas). Y será también por asociación con las fugas que Girondo traerá a colación «los acordes abismos de los órganos sacros del orgasmo" (8), un verso en el que la ambigüedad del significante órganos permitirá establecer a su vez un puente entre la serie musical y la sexual. De modo que, retrospectivamente, el noveno verso («el tacto incauto solo») podría leerse como una alusión al autoerotismo. Pero la ambigüedad del significante fuga permitía no sólo la introducción de la serie musical sino también la asociación con lo ido del séptimo verso: «lo impar ido» (7), mientras que "el ahonde» (7) del octavo se vinculaba, fónica y semánticamente, con «el fofo fondo" del segundo.

Baste entonces con estos ejemplos para verificar el principio de serialización, enumeración o catálogo a partir del cual se elaboran los poemas de $E n$ la masmédula, así como la naturaleza de los "puentes» que permiten pasar de un paradigma semántico o mimofónico a otro -lo que nos permite afirmar que toda serie es, en estos poemas, multiserial ${ }^{24}$. Estos puentes pueden ser construidos a partir de ciertas disemias como en los ejemplos de prefugas y órganos, disemias que incluso pueden funcionar in absentia como era el caso de la expresión plexo solar en "Tropos", capaz de establer un puente entre tropos, vientres y nervios; los grifosones o las neovoces, como en el caso de solicroo o la mencionada almamasa; las mimofonías en general, que logran instalar series superponiendo términos de campos semánticos heterogéneos; lo que podríamos llamar los puentes eufónicos, como en el caso del significante cicatrices de "Tropos», que permiten pasar de un eco sonoro (/cal: tocan) a otro (/cel: cenizas); y finalmente los propios despliegues de paradigmas semánticos (como el portuario o marítimo en "Tropos») que permiten irradiar series homofónicas heterogéneas. Cualquier palabra puede considerarse una mezcla, y como consecuencia un puente, para unir costas semánticas $\mathrm{u}$ homofónicas, y por eso los verdaderos protagonistas de los poemas de En la masmédula son menos las voces que las «subvoces», en los

24. A propósito de las series multiseriales, ver G. Deleuze, op. cit., pp. 50-56. 
dos sentidos de la palabra: los mimemas de los diversos significantes, pero también los términos concomitantes que, como las armónicas de una nota, subyacen, por asociación semántica, a cada elemento seleccionado.

\section{CONCLUSION}

No debería sorprendernos entonces que los poemas de En la masmédula resulten intraducibles, ya no porque se perdería la belleza de una forma eufónica, aunque se conservara el sentido, sino porque las asociaciones por homofonía generan, en la mayoría de los casos, las propias series semánticas. Las repeticiones fónicas ya no pueden considerarse ajenas a la producción de sentido, y es el caso de las remotivaciones por mimofonía o de las (auto)ficcionalizaciones de la lengua. En el verbo francés reverdir ya no encontraríamos los mimemas de voir y de être, como sucede con el reverdecer español, y mucho menos los hallaríamos en inglés, ya que deberíamos contentarnos con la expresión turn green again. Y sería difícil encontrar un equivalente de un grifosón como soplosorbos (47). Esta palabra-valija comporta, por empezar, una simetría semántica, ya que reúne los movimientos opuestos del aire en la boca: la expiración y la aspiración. Pero además, puede considerarse como un palíndromo, o como una simetría fónica, ya que los sonidos $/ p / / \mathrm{y} / \mathrm{r} b /$ suponen una metatesis dada la equivalencia fónica entre las dos consonantes bilabiales y las dos líquidas. De modo que soplosorbos resume en una palabra la operación dominante a lo largo de En la masmédula: la construcción de una secuencia por automimofonía.

A la manera de San Isidoro, Girondo trata la lengua como un saber criptográfico o criptofónico, cabalístico, acerca del mundo y sus criaturas, saber que la arbitrariedad del signo saussuriano negaba, saber que la hipótesis del inconsciente freudiano volverá a poner a la orden del día. A pesar de que a menudo se ha considerado a la metáfora como un saber precientífico, más cercano al conocimiento por semejanzas y analogías típico del medioevo que al de las identidades y las diferencias de la episteme moderna, este tropo deja intacto el postulado de la lingüística: el poeta encuentra analogías que la lengua, precisamente, ignoraba. Cuando el propio Girondo habla de aquellos fanales senos, introduce una proporción: los fanales (o faros) son a los barcos lo que los senos al yo poético. Pero esta metáfora podría traducirse a otras lenguas sin verse mayormente afectada. No sucedería lo mismo con las remotivaciones por homofonía. Ya no encontramos un je ni un moi mimetizados en la palabra francesa cobaye, ni un $I$ o un me en el guinea pig del inglés. 
Los poemas de En la masmédula se ven confinados entonces a la lengua española, precisamente porque no cesan de transgredir sus identidades léxicas y morfológicas a través de los mimetismos fónicos. Como afirma Jean-Claude Milner, una lengua es un modo singular de generar equívocos ${ }^{25}$, y la paradoja consiste en que la lingüística se preocupa por conjurarlos. Pero la paradoja de Milner se vuelve aun más flagrante cuando se picnsa que ese dominio de los equívocos o las mimofonías es el de la ficcionalización de la lengua, de una seudo-lengua, en donde los mimemas fingen o simulan otras palabras: la singularidad de una lengua es su propia ficción.

La lingüística, en este aspecto, es una aliada de la comunicación y no necesariamente de la poesía. La singularidad de la lengua se convierte para la primera en un excedente irrepresentable pero es el tesoro del lenguaje poético, por no decir el lenguaje poético mismo. Si en éste «toda similaridad aparente en el sonido será evaluada en términos de similaridad y/o disimilaridad en el sentido", según la citada definición de Jakobson, y una lengua es esa manera específica de suscitar malentendidos por homofonía, la ocasión para generar lapsus, retruécanos y etimologías apócrifas, de revelar palabras mimetizadas en otras palabras o de establecer catálogos estrafalarios por mimofonía, entonces el "genio" de cada lengua, como se lo llamó en otros tiempos, se revela en la poesía, allí donde el deseo se dice, sustrayéndose a la legalidad paterna y a los aparatos del realismo académico que pretenden velar sobre su pureza, su unidad o su hidalguía, allí donde la ficcionalización de la seudo-lengua se manifiesta como el ser propio, único e intraducible, de cada lengua.

25. "Un mode singulier de faire équivoque, voilà donc ce qu'est une langue entre autres». J.-C. Milner, op. cit., p. 22. 